\title{
20 AÑOS
}

Hace 20 años salía a la luz el primer número de la Revista Argentina de Antropología Biológica, la RAAB. La decisión de su creación surgió del éxito alcanzado en las Primeras Jornadas Nacionales de Antropología Biológica, realizadas en septiembre de 1993 en la ciudad de La Plata, evento en el que se presentaron más de 40 ponencias científicas. Los investigadores allí reunidos tuvieron conciencia del grado de desarrollo alcanzado por nuestra disciplina y se vieron estimulados a organizar la Asociación de Antropología Biológica Argentina, junto con su órgano de difusión. El objetivo de la RAAB, como se mencionaba en su primera edición, fue documentar la producción científica volcada en sucesivas Jornadas Nacionales.

La Antropología Biológica es una disciplina a la vez biológica y social y, por eso, presenta enormes oportunidades de crecimiento, tanto como recursos intelectuales para el intercambio de conocimiento y la colaboración con otras disciplinas. En este contexto, es un desafío lograr la continua formación de estudiantes y el desarrollo de temas originales, siendo expectativa de los editores pasados y presentes la reivindicación de la RAAB como oportunidad para la publicación de contenidos actualizados, abiertos y atravesados por múltiples enfoques para favorecer la apertura de la disciplina y la divulgación social del conocimiento científico. Sentadas las bases de los requerimientos disciplinares y académicos, uno de los mayores desafíos viene siendo lograr mayor visibilidad de los trabajos para lo cual la incorporación de la RAAB en bibliotecas electrónicas de jerarquía y el acceso abierto de los trabajos lo permiten. La participación a editores y revisores que trabajan por fuera del ámbito nacional, el registro de cada trabajo con un Digital Object Identifier (DOI) y el control antiplagio son también medios para aumentar la difusión y garantizar la calidad en el proceso de evaluación.

En tiempos de "publicar o perecer", consideramos que hay muchos modos formales e informales para crear y fortalecer la investigación; las publicaciones científicas son uno de ellos. Se convierten, sin embargo, en un medio primordial para la comunicación de la producción intelectual, creando vínculos entre pares a través de los procesos de evaluación y edición. Constituyen, además, un registro escrito, disponible para el futuro, de los contenidos que se han considerado aceptables por la comunidad científica de un determinado momento.

Es necesario celebrar que la RAAB haya mantenido continuidad durante 20 años, dando pasos para estar a la altura de las nuevas exigencias en materia de divulgación científica. Autores, revisores, editores y lectores, entre tantos otros, han colaborado para su consolidación. Celebrar cobra mayor relevancia en un país que ha pasado por diversos avatares políticos y económicos, algunos de los cuales afectaron severamente a las instituciones académicas y científicas.

No obstante, el principal reto para todos los profesionales de la Antropología Biológica es que la información publicada trascienda los gabinetes, laboratorios y congresos. Esto implica trabajar para que los contenidos nutran también espacios de gestión pública, de gobierno y de diálogo social.

Marina L. Sardi ${ }^{1}$

Francisco R. Carnese ${ }^{2}$

Graciela Bailliet $^{1}$ 